\title{
Squamous Cell Carcinoma of Tongue
}

\author{
Dr. Manas Bajpai \\ Assistant Professor, Department of Oral and Maxillofacial Pathology, \\ NIMS Dental College Jaipur, India \\ Dr. Nilesh Pardhe \\ Professor and Head, Department of Oral and Maxillofacial Pathology, \\ NIMS Dental College Jaipur, India
}

Keywords: Squamous cell carcinoma, Epidermoid carcinoma, tongue

A 57 year old Indian male presented to the Department of Oral and Maxillofacial Pathology, NIMS Dental College, Jaipur (India) with the chief complaint of painful non - healing ulcer of the tongue since the last one year. There had been a gradual increase in the size of the ulcer over the past 1 year. Patient was not able to perform normal movements of tongue. On history taking patient reported that he had been eating tobacco $8-10$ packets daily and smoking cigarettes from last 22 years. On physical examination cervical group of lymph nodes were found to be palpable. Intra - oral examination revealed a large ulcerative lesion redish - white in color of $5 \times 4 \mathrm{~cm}$ in dimension extending from lateral borders of the tongue to the dorsum of the tongue and postero - medially to the sulcus terminalis. The margins of the ulcer were irregular and indurated and the ulcer was covered with a fibrinous exudates. CT scan revealed a $15.6 \times 10.6 \mathrm{~mm}$ lesion extending from the lateral aspect of the tongue to the dorsum of the tongue. (Figure -1) Based on the clinical features provisional diagnosis of Squamous cell carcinoma was made.

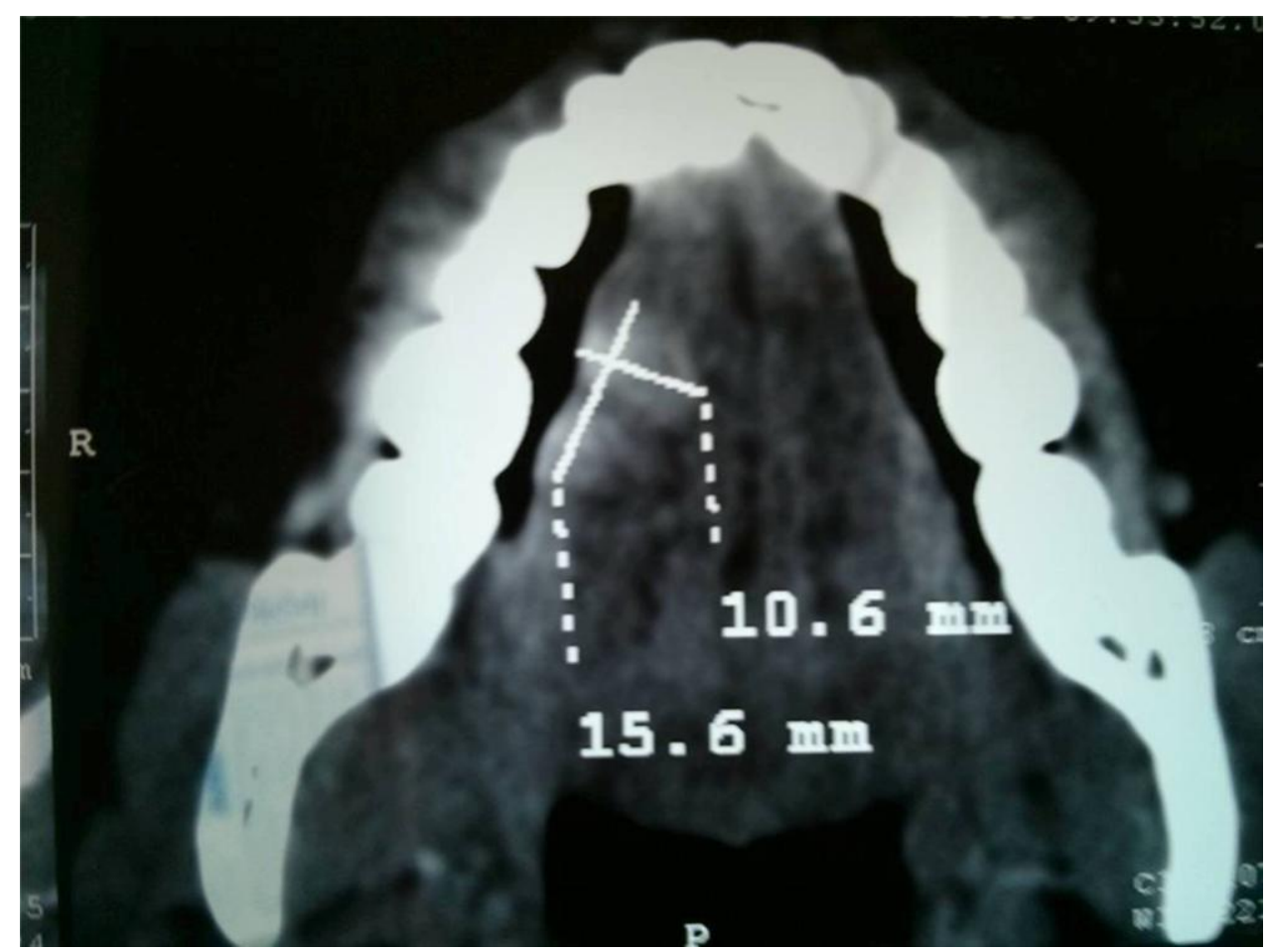

Figure 1. CT scan shows a large lesion extending from lateral border to the dorsum of the tongue. 
Hemiglossectomy was done under general anesthesia followed by reconstruction using radial forearm flap. A bilaterall modified radical neck dissection type III was performed. The excised tissue was sent for histopathological evaluation. (Figure - 2)

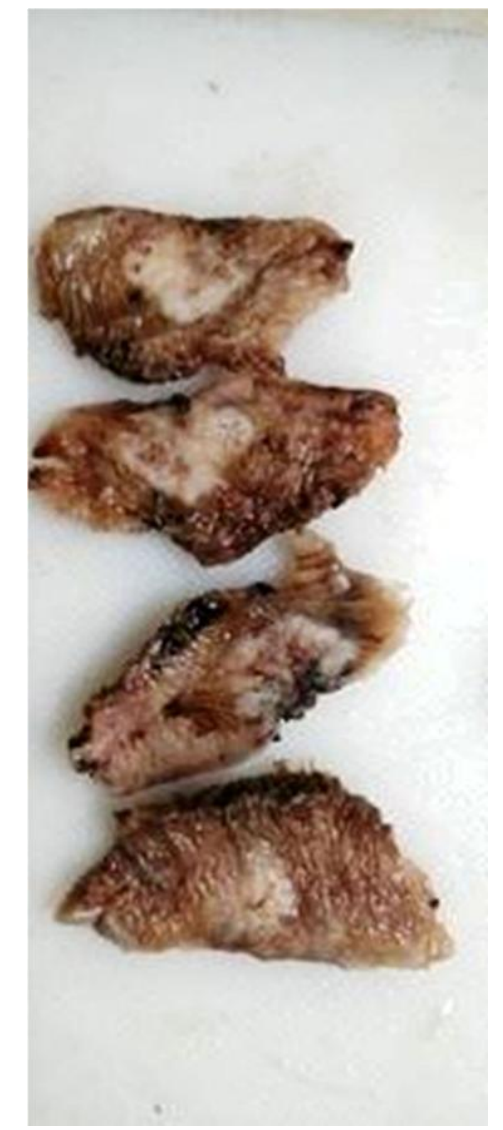

Figure 2. Gross tissue

Histopathological examination of soft tissue sections revealed dysplastic epithethial cells in connective tissue stroma in the form of chords \& islands. (Figure 3)

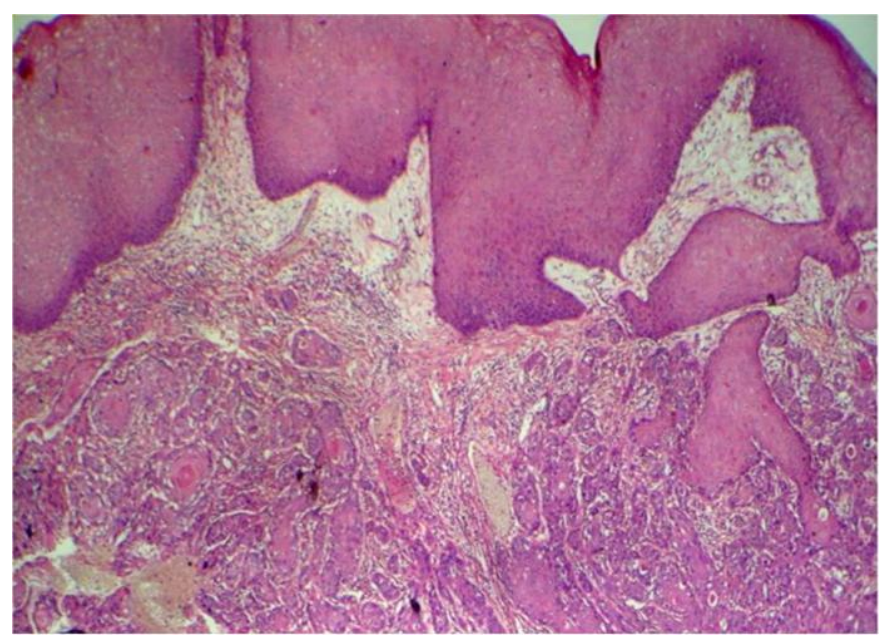

Figure 3. Islands of dysplastic epithelium invade connective tissue stroma. Overlying epithelium show broad rete ridges $(\mathrm{X} 100)$

The invaded cells shows cellular pleomorphism, nuclear hyperchromatism, increased nuclear to cytoplasmic ratio, (Figure 4) abnormal mitotic figures, individual cell keratinization and keratin pearl formation. (Figure 5) The intervening connective tissue stroma is sparse and is made up of collagen fibres, fibroblasts and fibrocytes and is densely infiltrated with chronic inflammatory cells chiefly lymphocytes. The overlying epithelium is highly dysplastic and is covered by fibrino-purulent material. Based on all the features final diagnosis of well differentiated squamous cell carcinoma was made. 
Squamous cell carcinoma is the most common malignancy affecting the oral cavity characterized by a chronic non healing ulcer which has a range of provisional diagnosis. ${ }^{1}$ SCC occurs more frequently in males, usually in the 5 to 6 th decade of life. ${ }^{2}$ The current case presented in an elderly male and the diagnosis was based on the clinical, radiological and histopathological examination. The classical presentation, with individual cell keratinization and keratin pearl formation, confirmed its resemblance to the parent tissue which validated its grading as a well differentiated tumor.

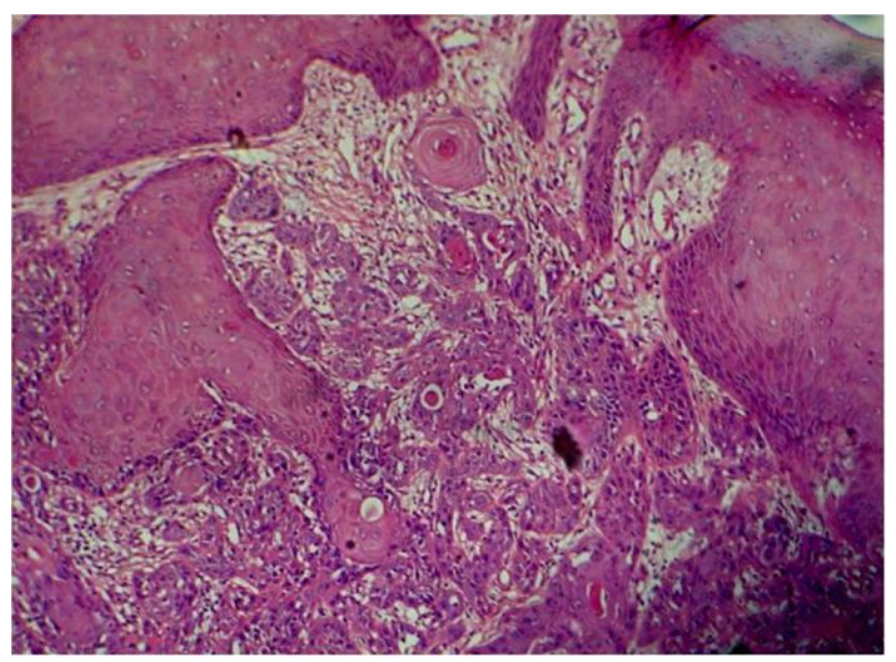

Figure 4. Epithelium shows dysplastic features like cellular pleomorphism and nuclear hyperchromatism. (X200)

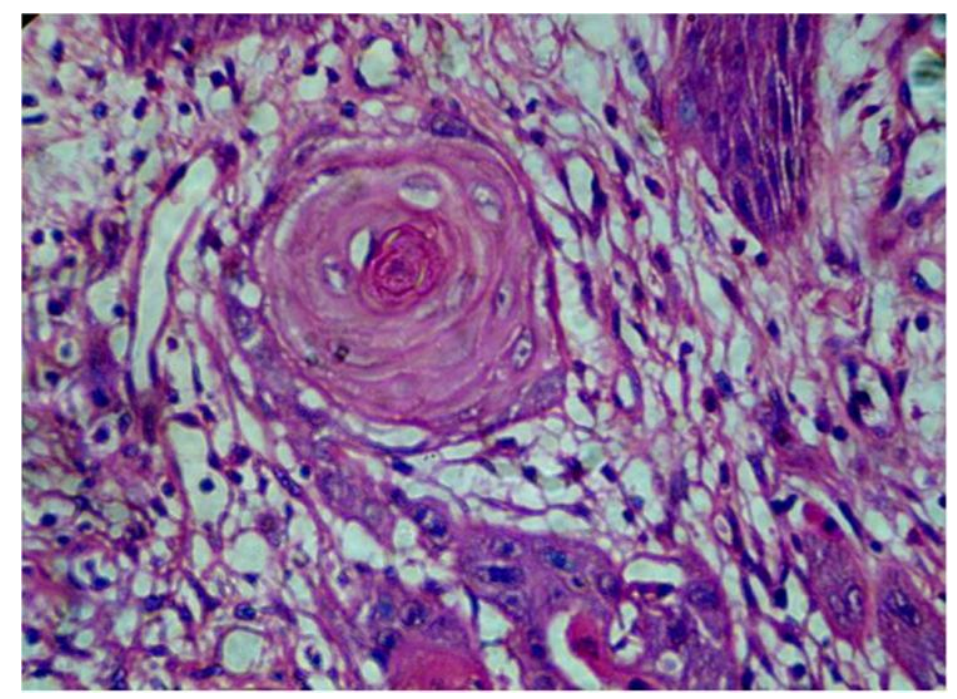

Figure 5. Keratin pearl is seen in the stroma (X400)

\section{REFERENCES}

[1] Anneroth G, Batsakis J (1987). Review of literature and a recommended system of malignancy grading in oral squamous cell carcinoma. Scand. J. Dent. Res. 95:229-429.

[2] Bryne M, Koppang HS, Lilleng R, Stene T, Bang G, Dabelsteen E (1989). New malignancy grading is a better prognostic indicator than Broders' grading in oral squamous cell carcinoma. J. Oral Pathol. Med. 18:432-437. 